\title{
Produção de serapilheira em fragmento de Floresta Estacional Subtropical na região norte do Rio Grande do Sul ${ }^{1}$
}

\author{
Grasiele Dick ${ }^{2}$; Márcia d'Ávila ${ }^{3}$; Mauro Valdir Schumacher ${ }^{4}$
}

\begin{abstract}
Resumo: A serapilheira desempenha um importante papel na manutenção da fertilidade em ecossistemas florestais naturais. Para tanto, o objetivo do presente trabalho foi avaliar a serapilheira produzida e seu estoque de carbono, bem como a relação com variáveis ambientais, em um fragmento de Floresta Estacional Subtropical, localizado no município de Frederico Westphalen, Rio Grande do Sul. Foram instalados de forma sistemática dezesseis coletores quadrados de $1 \mathrm{~m}^{2}$ de área, sendo oito coletores alocados no interior e oito na borda do fragmento. Durante o período de um ano, todo material vegetal produzido e depositado nos coletores foi removido mensalmente, acondicionado, identificado e levado para laboratório, para a secagem e determinação da massa seca. A serapilheira produzida foi $5,11 \mathrm{Mg} \mathrm{ha}^{-1}$ e o estoque de carbono foi de $2,56 \mathrm{Mg}^{-1}$. A menor produção de serapilheira foi observada no mês de maio de 2010 e a maior no mês de setembro de 2010 . A produção de serapilheira não apresentou correlação com a temperatura, mas sim com a precipitação, que influenciou a sazonalidade e o pico de maior devolução da mesma.
\end{abstract}

Palavras - chave: Fragmentação florestal; Biomassa; Carbono orgânico; Sazonalidade.

\section{Litterfall of a Subtropical Seasonal Forest in northern Rio Grande do Sul}

\begin{abstract}
Litterfall has an important role in the maintenance of fertility in natural forest ecosystems. Therefore, the objective of this study was to evaluate the litterfall produced and its carbon stock, and the relationship with environmental variables, in a fragment of a Subtropical Seasonal Forest, located in the city of Frederico Westphalen, northern region of Rio Grande do Sul state. Were installed systematically sixteen squares litter traps of $1 \mathrm{~m}^{2}$, eight collectors allocated within eight on the edge of the fragment. During the period of one year, all plant material produced and deposited in the collectors has been removed, identified and brought to the laboratory for determination of dry weight. The litter produced was $5.11 \mathrm{Mg}^{-1}$ and the carbon stock was $2.56 \mathrm{Mg} \mathrm{ha}^{-1}$. The lower production of litter was observed in the month of May 2010 and the largest in the month of September 2010. The litterfall was not correlated with temperature, but with the precipitation, which influenced the seasonal and peak greater devolution thereof.
\end{abstract}

Keywords: Forest fragmentation; Biomass; Organic carbon; Seasonality.

\footnotetext{
${ }^{1}$ Recebido em 03.12.2014 e aceito para publicação como artigo científico em 03.03.2015.

${ }^{2}$ Engenheira Florestal (UFSM); Msc., Doutoranda em Ecologia, solos e nutrição de florestas (PPGEF/UFSM). E-mail: <grasidick@hotmail.com>.

${ }^{3}$ Engenheira Florestal, Dra. Professora do departamento de Ciências Florestais do Centro de Educação Superior Norte RS (UFSM). E-mail: <davilamar@hotmail.com>.

${ }^{4}$ Engenheiro Florestal, Dr. nat. techn., Professor Titular do Departamento de Ciências Florestais, Universidade Federal de Santa Maria. Email:<mvschumacher@gmail.com>.
} 


\section{Introdução}

Atualmente a paisagem natural no estado do Rio Grande do Sul é caracterizada por fragmentos de floresta, dispostos em pequenas manchas esparsas entre lavouras agrícolas. As porções residuais de Florestas Estacionais Subtropicais encontram-se alteradas e parcialmente descaracterizadas, onde os remanescentes mais conservados estão nas pequenas propriedades rurais, principalmente nas encostas (KILCA e LONGHI, 2011).

De acordo com Vidal et al. (2007), a fragmentação de habitats, além de criar bordas, leva à formação de manchas remanescentes de habitat, com tamanhos variáveis e isoladas, sendo que, o tamanho do fragmento, bem como seu grau de isolamento também podem afetar a produção de serapilheira. Ao se comparar fragmentos florestais que se encontram na mesma situação climática e são provenientes do mesmo tipo vegetacional, por exemplo, esperase que aqueles pequenos e isolados, ou seja, mais degradados, produzam maiores massas de serapilheira em relação aos maiores e com menor isolamento.

A degradação dos ecossistemas florestais naturais implica em consequências negativas quanto à manutenção da biodiversidade, e também aos aspectos ligados ao sequestro de carbono da atmosfera. Com a redução no número de árvores por área, há menor incorporação do carbono nos distintos compartimentos da biomassa vegetal, uma vez que, de acordo com Taiz e Zeiger (2013) o $\mathrm{CO}_{2}$ é um elemento requerido nos processos de fotossíntese.

Considerando que a floresta tem elevada capacidade de fixação de carbono (SCHUMACHER et al., 2002; SANQUETA et al., 2002), as consequências do desmatamento estão diretamente relacionadas ao aumento do efeito estufa. Segundo Almeida et al. (2010), para redução da concentração do $\mathrm{CO}_{2}$ atmosférico, devem ser estudadas e empregadas estratégias de preservação de florestas nativas e principalmente o reflorestamento.

Ressalta-se que $85 \%$ do carbono orgânico é fixado pelas florestas, sendo este alocado nos compartimentos da biomassa arbórea, tais como folhas, galhos, casca, madeira (WATZLAWICK et al., 2002; BEGON et al., 2007), e também no solo e na serapilheira acumulada. Segundo Cianciaruso et al. (2006), a serapilheira é constituída por todo material vegetal, cujos componentes que a formam são predominantemente as folhas, ramos, raízes, frutos e sementes, bem como os restos de animais e material fecal, depositados no chão da floresta.

Depois de incorporado na biomassa, o carbono retido na serapilheira produzida retorna ao ambiente através da ação de organismos detritívoros e decompositores, presentes na fauna do solo, sendo que, quanto maior o teor de carbono e quantidade de serapilheira, mais lenta é a liberação deste elemento (BEGON et al., 2007).

Estudos abordando a produção de serapilheira, em áreas submetidas a distúrbios, são importantes para entender a relação desse compartimento com o processo regenerativo da vegetação (MARTINS e RODRIGUES, 1999). Segundo Vidal et al. (2007), entender os padrões de produção da serapilheira é fundamental para compreender a dinâmica e funcionamento dos ecossistemas.

Os estudos abrangendo o tema serapilheira vêm sendo pouco explorados neste âmbito, embora esta desempenhe um importante papel para a manutenção dos ecossistemas florestais (CASTRO e PIVELLO, 2008; POGGIANI e SCHUMACHER, 2005). Neste sentido, o presente estudo teve como objetivo avaliar a produção e estoque de carbono na serapilheira, bem como verificar a influência de variáveis climáticas, em um fragmento de Floresta Estacional Subtropical.

\section{Material e métodos}

Caracterização da área

$\mathrm{O}$ estudo foi realizado durante o período compreendido entre maio de 2010 a abril de 2011, no município de Frederico Westphalen, 
RS. A coordenada geográfica central da área é $53^{\circ} 25^{\prime} 59.26^{\prime \prime} \mathrm{O}$ e $27^{\circ} 23^{\prime} 44.40^{\prime}$ 'S, com altitude variando entre 520 a $550 \mathrm{~m}$ em relação ao nível do mar. Os dados referentes à produção de serapilheira foram obtidos em um fragmento de Floresta Estacional Subtropical com 34 ha de área, atualmente preservado, isento da remoção de madeira e pressão antrópica há 50 anos, cuja prática era intensiva antes do cercamento da área.

O clima da região, segundo a classificação de Köppen é do tipo subtropical (Cfa), com chuva bem distribuída durante o ano e temperatura média do mês mais quente superior a $22{ }^{\circ} \mathrm{C}$. A precipitação média anual varia entre $1.400 \mathrm{e}$ $1.760 \mathrm{~mm}$, bem distribuída ao longo do ano (MATZENAUER et al., 2011). O relevo é constituído pelo planalto basáltico, com predomínio de Latossolo Vermelho Distrófico, que são solos bem drenados normalmente profundos a muitos profundos (STRECK et al., 2008).

A vegetação do local é típica da formação da Floresta Estacional Subtropical, caracterizada por grande diversidade de espécies. Em um levantamento fitossociológico no mesmo fragmento deste estudo, Scipioni et al. (2011) verificaram a presença expressiva das espécies Bauhinia forficata, Balfourodendron riedelianum, Calliandra foliolosa, Eugenia burkartiana, Holocalyx balansae, Pilocarpus pennatifolius, Tetrorchidium rubrivenium e Diatenopteryx sorbifolia.

De acordo com Kilca e Longhi (2011) constatou-se que Cupania vernalis, Trichilia clausseni, Nectandra megapotamica, Myrcianthes pungens, Matayba elaeagnoides, Banara parviflora, Luehea divaricata, Chrysophyllum gonocarpum e Patagonula americana, também estão entre as espécies mais abundantes e frequentes nesta tipologia florestal.

Coleta de dados

A amostragem de serapilheira foi realizada com coletor quadrado fixo, de $1 \mathrm{~m}^{2}$ de área, alocado a $0,50 \mathrm{~m}$ de altura do solo. Os coletores foram confeccionado com tela de $2 \mathrm{~mm}$ de malha, sob apoios de madeira. Foram distribuídos 16 coletores no fragmento, sendo oito alocados na região considerada como borda, que foi compreendida em até $10 \mathrm{~m}$ a partir da área marginal da floresta, e oito coletores no interior da floresta, a partir de $250 \mathrm{~m}$ da margem. Manteve-se a distância mínima entre os coletores de $100 \mathrm{~m}$ na borda e $40 \mathrm{~m}$ no interior da floresta.

As coletas foram realizadas mensalmente, onde o material coletado, composto em sua maioria por folhas, foi identificado conforme a data e localização do coletor e acondicionado em saco plástico. Após coletada, a serapilheira foi levada ao laboratório, onde as amostras foram acondicionadas em sacos de papel e secas em estufa de circulação e renovação de ar a $65^{\circ} \mathrm{C}$, por $72 \mathrm{~h}$. A massa seca, em gramas, foi obtida através de balança com precisão de $0,01 \mathrm{~g}$ e os dados foram extrapolados para a estimativa de massa seca por hectare $\left(\mathrm{Mg} \mathrm{ha}^{-1}\right)$.

Os dados climáticos mensais de temperatura e precipitação da área foram obtidos da estação meteorológica experimental, instalada em área distanciada a $500 \mathrm{~m}$ do fragmento, que pertence ao Centro de Educação Superior Norte do RS.

A quantidade de carbono presente na serapilheira foi estimada multiplicando as respectivas estimativas de massa pelo fator 0,5 , ou seja, considerou-se que em média $50 \%$ da biomassa é composta por carbono (HIGUCHI e CARVALHO, 1994; KRAENZEL， 2002; SOARES e OLIVEIRA, 2002).

Análise dos dados

Para análise estatística da produção de serapilheira, utilizou-se o teste de Tukey $(\alpha=$ $5 \%$ ), considerando-se o delineamento inteiramente casualizado. Obteve-se também a correlação de Pearson entre a produção de serapilheira e variáveis climáticas médias de precipitação e temperatura mensais. As análises foram realizadas com auxílio do software Assistat versão 7.7 (SILVA e AZEVEDO, 2002). 


\section{Resultados e Discussão}

A produção total de serapilheira durante o período de estudo foi de $5,11 \mathrm{Mg} \mathrm{ha}^{-1}$, sendo que houve diferença estatística significativa quando se considerou a sazonalidade, com máximo de aporte na ordem de $0,9 \mathrm{Mg} \mathrm{ha}^{-1}$ no mês de setembro de 2010 e mínimo de $0,2 \mathrm{Mg} \mathrm{ha}^{-1}$ no mês de maio de 2010 (Figura 1).

Ou seja, o menor registro de queda de serapilheira ocorreu no período inicial do outono e, a maior produção ocorreu no início da primavera. Constatou-se produção semelhante de serapilheira entre os meses de julho, outubro (2010) e abril (2011), bem como nos meses de janeiro, fevereiro e março de 2011.

Quanto às correlações com as variáveis climáticas, a produção de serapilheira não esteve associada expressivamente com a temperatura, onde o coeficiente de Pearson resultou em -0,3. Já para a precipitação, a correlação foi positiva e considerada significativa, pois o coeficiente foi de 0,7 .

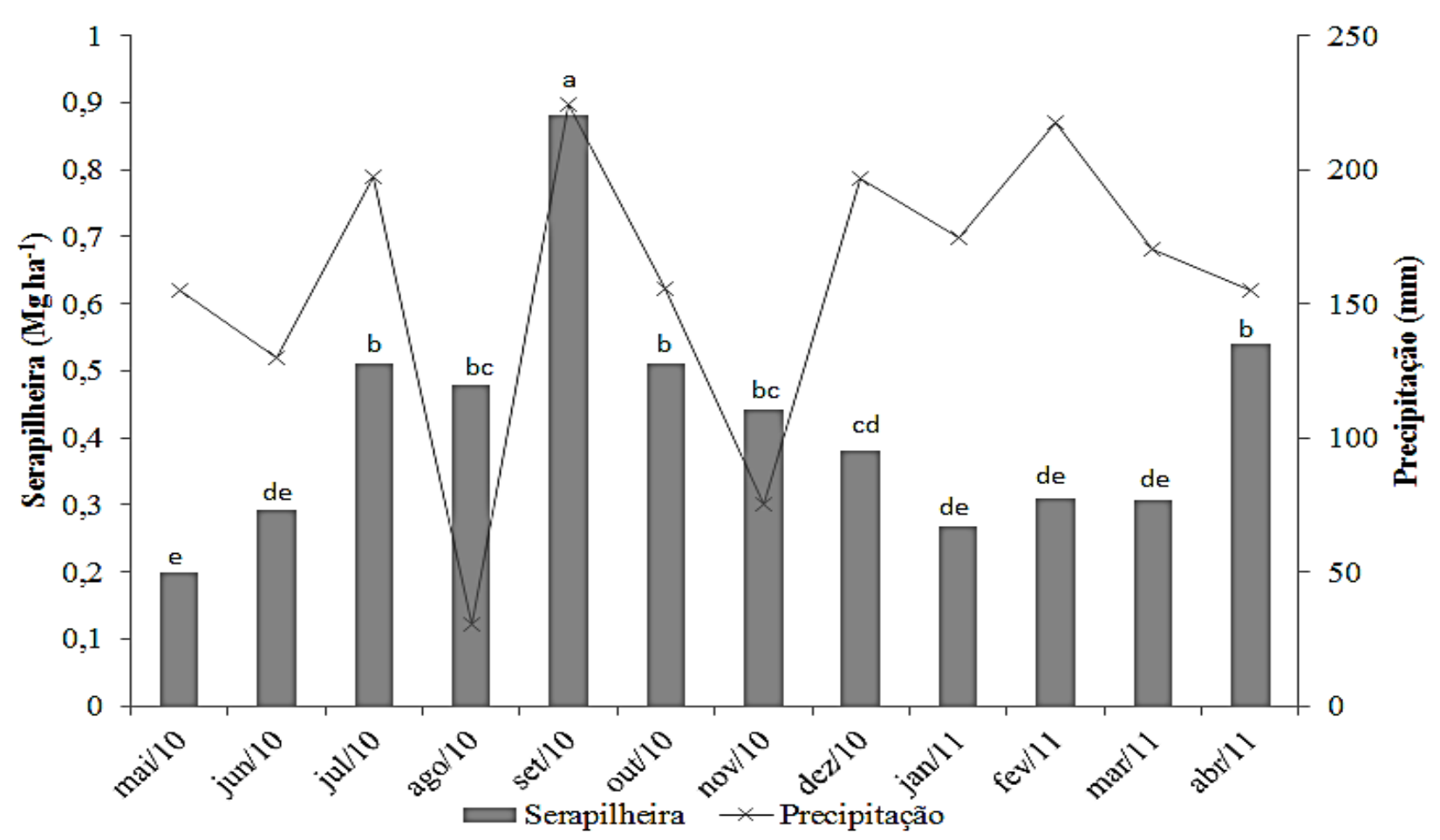

*Colunas seguidas pela mesma letra não diferem entre si pelo teste Tukey, considerando a probabilidade de 5\% de erro.

Figura 1: Sazonalidade da produção de serapilheira e relação com a precipitação média mensal, em um fragmento de Floresta Estacional Subtropical, em Frederico Westphalen/RS.

Figure 1: Seasonality of litter production and compared with the average monthly precipitation, of a Subtropical Seasonal Forest in Frederico Westphalen/RS.

Em decorrência do caráter decidual da Floresta Estacional, em geral, pode ser observada maior produção de serapilheira nos meses de temperaturas mais amenas. $\mathrm{O}$ mesmo resultado foi observado por König et al. (2002), onde as maiores produções ocorreram entre julho e setembro, no período de inverno, e as menores entre outubro e abril, na primavera e no verão. Isto ocorre, pois, segundo Poggiani (2012), a chegada das estações do outono e inverno, acompanhada do resfriamento e encurtamento dos dias, é o fenômeno que 
desencadeia a derrubada completa das folhas em florestas caducifólias.

Em floresta Atlântica secundária, Vidal et al. (2007), observaram que a maior produção de serapilheira ocorreu no período de agosto à janeiro, coincidindo com o período onde houve maior incidência de precipitação, que antecedeu o período de seca, de março à julho, onde a produção foi menor. Os autores também concluíram que houve relação entre o tamanho e estado de conservação do fragmento florestal com a deposição de serapilheira, pois, quanto menor e mais impactado a área, maior foi o investimento em aporte de serapilheira.

No caso do presente estudo, não houve correlação com a temperatura, no entanto, a maior produção de serapilheira em setembro esteve relacionada à precipitação, que foi mais elevada neste mês, pois chuvas fortes promovem a queda de muitos ramos secos, que ainda permaneciam unidos à planta (VIDAL et al., 2007; MORAES et al., 1999). Além disto, a menor quantidade de chuva registrada no mês anterior (agosto) induziu a expressiva queda de serapilheira no mês seguinte, em função da condição de estresse às plantas (TAIZ e ZEIGER, 2013).

König et al. (2002) atribuem em seu estudo que, o grande pico de devolução de serapilheira no mês de setembro está associado à composição predominante das espécies que compõem a Floresta Estacional Subtropical, obedecendo a um padrão quanto à derrubada das folhas no final do período de seca fisiológica, em virtude das baixas temperaturas.

Em estudo avaliando a produção de serapilheira em Floresta Ombrófila Mista, Figueiredo Filho et al. (2003) também verificaram diferenças quanto à sazonalidade, com maior aporte na estação da primavera $(2,43$ $\left.\mathrm{Mg} \mathrm{ha}^{-1}\right)$, seguido do inverno $\left(2,16 \mathrm{Mg} \mathrm{ha}^{-1}\right)$, após o verão $\left(1,76 \mathrm{Mg} \mathrm{ha}^{-1}\right)$ e outono $(1,33 \mathrm{Mg}$ $\mathrm{ha}^{-1}$ ).

Ao avaliarem a deposição de serapilheira em Floresta Estacional Subtropical, alguns autores encontraram resultados semelhantes ao do presente estudo, sendo que, Schumacher et al. (2011) em floresta sobre Neossolo, na região central do Rio Grande do Sul, constatou produção de $5,85 \mathrm{Mg} \mathrm{ha}^{-1}$ de serapilheira, König et al. (2002) constataram aporte de 9,2 $\mathrm{Mg} \mathrm{ha}^{-1}$ em um fragmento alterado e Cunha et al. (1993) relatou produção de 7,7 $\mathrm{Mg} \mathrm{ha}^{-1}$.

Avaliando a produção de serapilheira em função da regeneração natural das florestas, Brun et al. (2011) estudaram três fases sucessionais e relataram produção semelhante a deste estudo. No estágio denominado "floresta inicial", com 27 anos, onde houve queda de 6,5 $\mathrm{Mg} \mathrm{ha}^{-1}$; na fase de "floresta secundária", com 50 anos, a produção foi de $7,4 \mathrm{Mg} \mathrm{ha}^{-1}$; no estágio de "floresta madura", com mais de 100 anos, ocorreu maior aporte de serapilheira, com 9,7 $\mathrm{Mg} \mathrm{ha}^{-1}$.

Pinto et al. (2008) também compararam a produção de serapilheira em função do estágio suscessional em Floresta Estacional Semidecidual, em Minas Gerais, e verificaram o mesmo comportamento de aumento na produção quando a sucessão é mais avançada, sendo que, em floresta "inicial" as autores encontraram 6,3 $\mathrm{Mg} \mathrm{ha}^{-1}$ em floresta "madura" 8,8 $\mathrm{Mg} \mathrm{ha}^{-1}$.

Em estudos na Floresta Atlântica, Calvi et al. (2009) e Toledo et al. (2002), avaliaram a produção de serapilheira em florestas secundárias e registraram aporte de 5,7 $\mathrm{Mg} \mathrm{ha}^{-1}$ e 4,03 $\mathrm{Mg} \mathrm{ha}^{-1}$, respectivamente.

Percebe-se que a produção de serapilheira está intimamente associada ao estado de conservação e regeneração do ecossistema florestal, considerando que, a área está em processo de sucessão secundária, com presença de espécies típicas deste estágio de regeneração. Conforme observado por Scipioni et al. (2011), que realizaram um levantamento fitossociológico na mesma área do estudo, constatando que espécies consideradas pioneiras e secundárias, tais como Gymnanthes concolor, Trichilia claussenni, Sorocea bonplandii, Chrysophyllum marginatum e Eugenia schuechiana são mais expressivas e de ampla ocupação no fragmento estudado, em decorrência das pretéritas atividades exploratórias.

Os resultados de produção de serapilheira deste estudo se assemelharam àqueles realizados 
em florestas secundárias em processo regenerativo, independentemente da tipologia florestal. No entanto, de uma forma geral, pode ser verificada baixa produção de serapilheira em fragmentos de Floresta Estacional Subtropical no Rio Grande do Sul, que em sua maioria estão ou já passaram por processos de degradação florestal, exceto em áreas de encostas onde o difícil acesso limita a extração de madeira e conversão do uso do solo, principalmente (KILCA e LONHGI, 2011).

Considerando a produção total de serapilheira no fragmento florestal, estimou-se que houve estoque de 2,56 $\mathrm{Mg} \mathrm{ha}^{-1}$ de carbono orgânico, presente no material vegetal senescente, que irá retornar ao solo após decomposição destes resíduos, compostos, neste caso, primordialmente por folhas e galhos finos (POGGIANI, 2012) .

Resultados semelhantes foram constatados por Watzlawick et al. (2002), em estudo na Floresta Ombrófila Mista Montana, procedendo pela estratificação da produção de serapilheira conforme o estágio sucessional da floresta, encontrou valores médios de carbono orgânico na ordem de 2,99 $\mathrm{Mg} \mathrm{ha}^{-1}, 3,30 \mathrm{Mg} \mathrm{ha}^{-1}$ e 2,90 $\mathrm{Mg} \mathrm{ha}^{-1}$, para as etapas de regeneração inicial, intermediária e avançada, respectivamente.

Pode-se observar que a serapilheira contém carbono em grandeza aproximada às florestas nativas quando se comparam aos estudos em povoamentos de fins comerciais, sendo que, alguns autores avaliaram a serapilheira acumulada, como no caso do Pinus taeda, com 22 anos, onde Watzlawick et al. (2005) verificaram que, a serapilheira sobre o solo continha 3,92 $\mathrm{Mg} \mathrm{ha}^{-1}$ de carbono orgânico.

Para Tectona grandis com 5,5 anos, Almeida et al. (2010) determinaram o teor de carbono na serapilheira e obtiveram 2,68 $\mathrm{Mg} \mathrm{ha}^{-1}$. Já para Eucalyptus, aos 2, 4, 6 e 8 anos de idade do povoamento, Witschoreck e Schumacher (2000) encontraram 1,65 $\mathrm{Mg} \mathrm{ha}^{-1}, 2,62 \mathrm{Mg} \mathrm{ha}^{-1}, 4,78$ $\mathrm{Mg} \mathrm{ha}{ }^{-1}$ e 5,5 Mg ha de serapilheira, respectivamente.

As oscilações na quantidade de carbono podem ser atribuídas à quantidade de deposição de serapilheira que está relacionada com a queda dos ramos e folhas, além da época de amostragem e o grau de decomposição da biomassa (SCHUMACHER et al., 2003), que por sua vez é ainda afetado pelas características do clima e solo, que condicionarão o teor de carbono da serapilheira (WITSCHORECK e SCHUMACHER, 2000).

\section{Conclusões}

Concluiu-se que a produção da serapilheira no fragmento de Floresta Estacional Subtropical foi sazonal, com influência expressiva da precipitação nos picos de aporte. $\mathrm{O}$ carbono orgânico fixado na serapilheira se assemelhou às outras formações florestais e até mesmo povoamentos florestais. Ressalta-se a importância da serapilheira na dinâmica do ecossistema florestal, além do papel na fixação do carbono.

\section{Agradecimentos}

Os autores agradecem a FIPE Jr. pela concessão de bolsa de pesquisa para desenvolvimento deste trabalho; ao Centro de Educação Superior Norte RS e Colégio Agrícola de Frederico Westphalen pela disponibilização da área de estudo.

\section{Referências}

ALMEIDA, E.M. et al. Determinação do estoque de carbono em teca (Tectona grandis L. F.) em diferentes idades. Ciência Florestal, Santa Maria, v. 20, n. 4, p. 559-568, out.-dez., 2010.

BEGON, M.; TOWNSEND, C.R.; HARPER, J.L. Ecologia: de indivíduos a ecossistemas. $4^{\text {a }}$ ed. Porto Alegre: Artmed, 2007. 752 p.

BRUN, E.J. et al. Aspectos da ciclagem do material orgânico e nutrientes na serapilheira de florestas secundárias em Santa Tereza. In: 
SCHUMACHER, M. V.; et al. (eds). A Floresta Estacional Subtropical: caracterização e ecologia no rebordo do Planalto Meridional. Santa Maria, Santa Maria: Pallotti, 2011. 320 p.

CALVI, G.P. et al. Produção de serapilheira e aporte de nutrientes em áreas de floresta atlântica em Santa Maria de Jetibá, ES. Ciência Florestal, Santa Maria, v. 19, n. 2, p. 131-138. 2009.

CASTRO, D. M.; PIVELLO, V. R. Efeitos de borda sobre a serapilheira em fragmentos de Cerradão, na região nordeste do estado de São Paulo, derivados do manejo agrícola. Anais... In: IX Simpósio Nacional Cerrado. Brasília-DF. 2008 .

CIANCIARUSO, M. C. et al. Produção de serapilheira e decomposição do material foliar em um cerradão na Estação Ecológica de Jataí, município de Luiz Antônio, SP. Brasil. Acta Botânica Brasilica, São Paulo, v. 20, n. 1, p. 4959. 2006.

CUNHA, G.C. et al. Dinâmica nutricional em Floresta Estacional Decidual com ênfase aos minerais provenientes da deposição da serapilheira. Ciência Florestal, Santa Maria, v.3, n.1, p. 35-64, 1993.

FIGUEIREDO FILHO, A. et al. Avaliação estacional da deposição de serapilheira em uma Floresta Ombrófila Mista localizada no sul do estado do Paraná. Ciência Florestal, Santa Maria, v. 13, n. 1, p. 11-18. 2003.

HIGUCHI, N.; CARVALHO, J. A. Fitomassa e conteúdo de carbono de espécies arbóreas da Amazônia. In: Seminário "Emissões e sequestro de $\mathrm{CO}_{2}$ - Uma nova oportunidade de negócios para o Brasil". Rio de Janeiro. Anais... Rio de Janeiro: CVRD-Companhia Vale do Rio Doce, 1994. p.127-153, 1994.

KILCA, R.V.; LONGHI, S.J. A composição florística e estrutura das flroestas secundárias no rebordo do Planalto Meridional. In:
SCHUMACHER, M. V. et al. (eds). A Floresta Estacional Subtropical: caracterização e ecologia no rebordo do Planalto Meridional. Santa Maria, 2011, 320 p.

KÖNIG, F. G. et al. Avaliação da sazonalidade da produção de serapilheira numa Floresta Estacional Decidual no município de Santa Maria-RS. R. Árvore, Viçosa, v.26, n.4, p. 429435, 2002.

KRAENZEL, M. Carbon storage of harvest age teka (Tectona grandis L.f.) plantations, Panama. Forest Ecology and Management, n.5863, p. 1-13, 2002.

MARTINS, S. V.; RODRIGUES, R. R. Produção de serapilheira em clareiras de uma Floresta Estacional Semidecidual no município de Campinas, SP. Revista Brasileira de Botânica, v.22, p.405-412, 1999.

MATZENAUER, R.; RADIN, B.; ALMEIDA, I. R. (Ed.). Atlas Climático: Rio Grande do Sul. Porto Alegre: Secretaria da Agricultura Pecuária e Agronegócio; Fundação Estadual de Pesquisa Agropecuária (FEPAGRO), 2011.

MORAES, R. M. et al. Litterfall and litter nutrient content in two Brazilian Tropical Forests. Rev. bras. Bot. [online], vol.22, n.1, p.09-16, 1999.

PINTO, S. I. C. et al. Produção de serapilheira em dois estádios sucessionais de Floresta Estacional Semidecidual na Reserva Mata do Paraíso, em Viçosa, MG. R. Árvore, ViçosaMG, v.32, n.3, p.545-556, 2008.99.

POGGIANI, F. Ciclagem de nutrientes em Florestas do Brasil. In: MARTINS, S.V. (Org). Ecologia de Florestas Tropicais no Brasil. Viçosa, MG. Ed.: UFV, 2012. p 371.

POGGIANI, F.; SCHUMACHER, M.V. Ciclagem de nutrientes em florestas nativas. In: GONÇALVES, J.L.M.; BENEDETTI, V. Nutrição e Fertilização Florestal. Piracicaba: 
IPEF, 2005, 427 p.

SANQUETTA, C.R. et al. (eds.). As florestas e o carbono. UFPR, Curitiba. 2002. 256 p.

SCHUMACHER, M.V.; et al. Espécies predominantes na deposição de serapilheira em fragmento de Floresta Estacional Decidual no Rio Grande do Sul. Ciência Florestal, Santa Maria, v. 21, n. 3, p. 479-486, jul.-set., 2011.

SCHUMACHER, M.V. et al. Retorno de nutrientes via deposição de serapilheira em um povoamento de acácia-negra (Acacia mearnsii De Wild.) no Estado do Rio Grande do Sul. Revista Árvore, Viçosa, v. 27, n. 6, p. 791-798, 2003.

SCHUMACHER, M.V.; et al. Estoque de carbono em florestas de Pinus taeda L. e Acacia mearnsii De Wild. plantadas no estado do Rio Grande do Sul - Brasil. In: SANQUETTA, C.R.; et al. (eds.). As florestas e o carbono. UFPR, Curitiba. 2002. 256 p.

SCIPIONI, M.C. et al. Fitossociologia em fragmento florestal no Noroeste do Estado do Rio Grande do Sul. Ciência Florestal, Santa Maria, v. 21, n. 3, p. 407-417, 2011.

SILVA, F. de. S.; AZEVEDO, C. A. V. de. Versão do programa computacional ASSISTAT para o sistema operacional Windows. Revista Brasileira de Produtos Agroindustriais, Campina Grande, v.4, n.1, p.71-78, 2002.

SOARES, C. P. B.; OLIVEIRA, M. L. R. Equações para estimar a quantidade de carbono na parte aérea de árvores de eucalipto em Viçosa, Minas Gerais. Revista Árvore, Viçosa, v. 26, n. 5, p. 534-539, 2002.

STRECK, E. V.; et al. Solos do Rio Grande do Sul. 2. ed. Porto Alegre: EMATER/RS, 2008. $222 \mathrm{p}$.

TAIZ, L.; ZEIGER. E. Fisiologia Vegetal. 5 ed. Porto Alegre/RS, Artmed, 2013. 918p.
TOLEDO, L.O. et al. Produção de serapilheira e transferência de nutrientes em florestas secundárias localizadas na região de Pinheiral, RJ. Ciência Florestal, Santa Maria, v. 12, n. 2, p. 9 -16. 2002.

VIDAL, M.M. et al. Produção de serapilheira em floresta Atlântica secundária numa paisagem fragmentada (Ibiúna, SP): importância da borda e tamanho dos fragmentos. Revista Brasil. Bot., V.30, n.3, p.521-532, jul.-set. 2007

WATZLAWICK, L.F. et al. Estoque de carbono orgânico e biomassa em Pinus taeda L. Biomassa e Energia. v.2. n.1. p. 7-17. 2005.

WATZLAWICK, L.F.; et al. Fixação de carbono em Floresta Ombrófila Mista em diferentes estágios de regeneração. In: SANQUETTA, C.R.; et al. (eds.). As florestas e o carbono. UFPR, Curitiba. 2002. 256 p.

WITSCHORECK, R.; SCHUMACHER, M.V. Estimativa do carbono da serapilheira em florestas de eucalipto de diferentes idades. Anais... In: Anais do $8^{\circ}$ Congresso Florestal Estadual de Nova Prata; 2000; Nova Prata. 2000. 